\title{
Da antiga à nova Carta de Atenas - em busca de um paradigma espacial de sustentabilidade
}

From ancient charter to the new Charter of Athens - a search
of a spatial paradigm of sustainability

\author{
Milena KANASHIRO ${ }^{1}$
}

RESUMO

\begin{abstract}
As visões da Carta de Atenas (1933) assumiram caráter dogmático, influenciando profundamente as nossas cidades. A proposição da cidade funcional como crítica às cidades tradicionais definia funções básicas: habitar, trabalhar, recrear e circular. Frente à considerada obsolescência do tecido urbano existente, impunha-se uma nova ordem, implicando, em termos formais, em um produto homogêneo. Nas últimas décadas emerge a discussão do conceito chamado desenvolvimento sustentável, que objetiva a manutenção da qualidade de vida, assegura acesso continuo aos recursos naturais e evita a persistência dos danos ambientais. Sob esse enfoque, a Nova Carta de Atenas (1998), resultado da discussão de onze países da Comunidade Européia, delineia temas emergentes. $\mathrm{O}$ trabalho traz um breve panorama do repensar urbano, apresenta os princípios, o paradigma proposto e delineia considerações sobre a Nova Carta.
\end{abstract}

Palavras-chave: Carta de Atenas (1933), Nova Carta de Atenas (1998), cidade sustentável.

\begin{abstract}
The visions of 1933 Athens Charter assumed a dogmatic character that is continually influencing our cities. The proposal of a functional city, as a critic of traditional spaces, was defined by its basic functions: dwelling, work (or production), recreation and transportation. Facing the existing obsolete urban tissue, a new order was imposed, having as result a homogeneous space, in formal terms. In the last decades the discussion of the concept of sustainable development has emerged aiming as maintaining life quality, ensuring continuous accessibility to the natural resources and avoiding the environmental damages. As a consequence, the 1998 Athens New Charter, resulting from the discussion of eleven countries of European Union witch defines an emergencies has emerged thematic. This paper deals with a brief panorama of the urban re-thinking, present the set of recommendations, expose the paradigm and outline considerations of the New Charter.
\end{abstract}

Key-words: 1933 Athens Charter, 1998 Athens New Charter, sustainable city.

1 Arquiteta, Doutoranda do Curso de Meio Ambiente e Desenvolvimento da UFPR, Docente do Centro de Tecnologia e Urbanismo da UEL 


\section{Introdução}

Na história das cidades, as imagens de perfeição têm produzido paradigmas como resultado de um desejo utópico de ordenamento e organização do espaço. Um dos paradigmas que talvez tenha influência sem precedentes foi a Carta de Atenas de 1933, resultado do IV CIAM (Congresso Internacional de Arquitetura Moderna). O documento preconizava a organização da cidade a partir de quatro funções básicas: trabalhar, habitar, circular e cultivar o corpo e o espírito, basicamente o gérmen da idéia da zonificação.

Sessenta e cinco anos depois, a Comunidade Européia, representada por onze países, publica o documento intitulado New Charter of Athens (1998) rediscutindo questões urbanas "mais apropriadas para os nossos tempos". Este trabalho traz, primeiramente, um breve panorama do repensar urbanístico; em seguida, apresenta os princípios da Nova Carta de Atenas; e, por fim, as reflexões que definem a complexidade e a emergência da discussão sobre a busca de um paradigma espacial de sustentabilidade urbana.

\section{Breve panorama do repensar urbanístico}

Segundo Choay, a palavra Urbanismo é relativamente recente e corresponde à nova realidade da expansão da sociedade industrial, tendo um caráter tanto reflexivo como crítico (CHOAY, 1979). Por assumir este viés de planejar e organizar a sociedade industrial em novas funções sobre antigas estruturas urbanas, diferencia-se dos precedentes históricos do Urbanismo Clássico.

Ao longo do Século XIX, ressaltam-se preocupações quanto à qualidade de vida e aos limites de crescimento e expansão de cidades. Ruskin e Louis Waurin alertam para as condições de vida dos operários e Owen cria as Trade Unions. O Falanstério de Fourier, a Cidade Linear de Arturo Soria e Mata, a cidade-jardim de Ebenezer Howard são exemplos de modelos utópicos que procuravam soluções para a situação de injustiça social instaurada nas cidades industriais (MAGALHÃES, 2001).

As primeiras medidas para conter os excessivos problemas advindos do rápido processo de industrialização e urbanização foram por meio das idéias sanitaristas frente às condições precárias de moradia da classe trabalhadora. Os Atos de Saúde Pública ingleses prescreviam padrões mínimos de moradias urbanas, baseados na estabilidade das construções, prevenção de incêndio e principalmente questões de saúde, desde larguras de novos arruamentos, drenagem, ventilação, entre outros (BROADBENT, 1996).

Várias correntes de pensamentos urbanos conceberam modelos e planos de reorganização das cidades. Muitas delas tinham ideais opostos, como por exemplo aquelas que ressaltavam as qualidades espaciais das cidades antigas e outras atreladas ao progresso e às descobertas técnicas. A chamada corrente progressista de organização das cidades, surgida já na era industrial e concomitante às necessidades do capitalismo, teve uma maior hegemonia nos pensamentos do urbanismo.

Neste contexto, o documento de divulgação conhecido como "Carta de Atenas", resultado do IV CIAM (Congresso Internacional de Arquitetura Moderna de 1933), definia como elementos do urbanismo o sol, o verde e o espaço e que por meio da organização das funções-chavetrabalhar, habitar, circular e recrear, que seriam autônomas entre si-,dar-se-ia a organização da sociedade na cidade contemporânea. Tal concepção está na base do Planejamento Urbano, considerado instrumento básico de ordenação de cidades e que reflete os ideais do funcionalismo a partir do zoneamento do uso do solo. Por meio de planos de caráter regulatório, o modelo propõe diretrizes e metas como uso, controle de expansão, áreas verdes, densidades de ocupação, entre outros. De maneira geral, os planos urbanos eram tratados tendo como base estatísticas e dados, planos de alocação de recursos e zoneamento como áreas homogêneas.

Ideologicamente, o Estilo Internacional difundido pelo Urbanismo Moderno estava atrelado às questões do homem-tipo (biologicamente idêntico independentemente de seus valores sociais e culturais) e, conseqüentemente, à habitação como uma "máquina de morar". Admitindo um modelo de homem universal, reduz-se a vida urbana àquelas quatro funções básicas e ignoram-se as condições específicas do local tanto em termos físico-ambientais quanto socioculturais. Surgem concepções de cidades baseadas em princípios formais e funcionais, com tendência a uma maior homogeneização dos espaços urbanos. Exemplos paradigmáticos são Brasília e Chandighard.

No entanto, na década de 60 , emergiram discussões da forma como o desenvolvimento vinha ocorrendo, questionando a fragmentação das ciências e o apoio até então incontestável do progresso da tecnologia. Tal contexto pode ser observado em várias ciências, com a revalorização das ciências sociais que resultou em uma maior preocupação em relação às questões ambientais. Segundo Floriani 
(2001), as desestabilizações ocorridas nas ciências pela crítica social e pela "invasão" de problemáticas forçam o aparecimento de novas fronteiras e novos campos de saber, por meio de disciplinas teórico-práticas, bem como objetos interdisciplinares de conhecimento.

No campo urbano, destacam-se alguns questionamentos para novas discussões, apoiadas nas críticas da cidade resultante moderna. Conforme Vicentini, a cidade razão para o século XX, a qual é recorrente à cidade-máquina, buscava modelar uma homogeneidade de modos de vida e consumo. Destacam-se algumas características, entre elas a perda do sentido de "lugar" na cidade do movimento moderno, a alegoria de um mundo homogêneo e a abordagem da natureza como resultado de fabricações do homem (VICENTINI, s/d).

Críticas quanto à falência do planejamento das cidades pela falta de inserção de elementos necessários da vida cotidiana foi ressaltada por Jane Jacobs, com a publicação do livro "Morte e Vida nas Grandes Cidades Americanas" (1961); a falta de compreensão das relações entre os distintos elementos e a comparação da cidade como uma grande forma coletiva, articulada, explícita e omitida, é observado por Fumihiko Maki em "A Forma Coletiva” (1964); por meio do uso da metáfora de que a cidade não pode ser entendida como uma árvore, é evidenciada a complexidade das várias redes de relações existentes no ambiente urbano, ignoradas nas formas tradicionais de planejar por Christopher Alexander em "A Cidade não é uma Árvore" (1965); a contestação da sistemática perda de qualidade urbana nas expansões modernistas e a reabilitação de cidades é enfatizada por Robert Krier em "Espaço Urbano" (1975).

O panorama de mudança questionava a qualidade do ambiente construído de nossas cidades baseada na idéia desenvolvimentista, que desconsiderava valores da população, a complexidade da vida urbana, do patrimônio histórico, da integração e inter-relação entre as funções e atividades humanas, a importância das redes sociais estabelecidas, dos valores afetivos e de tantos outros (DEL RIO, 1990).

Ao comparar a evolução do pensamento urbanístico no século XX, no sentido de acontecimentos dos fatos, observa-se que no intervalo entre a Carta de Atenas de 1933 e a Nova Carta de Atenas de 1998 a emergência de valores ambientais, culturais e históricos é incorporados na dis- cussão para a definição de novos ideais para a cidade do século XXI.

\section{Sobre a Nova Carta de Atenas}

O breve panorama do repensar urbano se fez necessário para indicar o direcionamento das discussões resultantes na Nova Carta de Atenas (1998). A Nova Carta de Atenas tem como objetivos gerais definir uma agenda urbana e conseqüentemente o papel do Planejamento Urbano, e finaliza com recomendações e princípios norteadores. Enfatiza que a formatação do documento resulta de uma série de discussões realizadas no âmbito europeu durante a década de 90. Entre os mais importantes estão o Green Paper on the Urban Environment (1990), Europe 2000. Outlook for the Development of Community's Territory (1991), Europe 2000 +: Co-operation for European Territorial Development (1994), European Sustainable Cities: Reported by the Expert Group on Urban Environment (1996) e Towards an Urban Agenda in the European Union (1997).

Tais documentos delineiam um número de temáticas relacionadas com a emergência desta nova Agenda, enfatizando a ação em quatro pontos-chave: promover competitividade econômica e emprego; favorecer coesão social e econômica; melhorar o transporte; e promover o desenvolvimento sustentável e a qualidade de vida. Um panorama analítico é delineado em dez itens, os quais definem as recomendações finais do documento, a saber: demografia e habitação, questões sociais, cultura e educação, sociedade informatizada, meio ambiente, economia, movimento, escolha e diversidade, segurança e saúde.

A síntese de uma forma urbana desejável para uma cidade sustentável é direcionada para a idealização da cidade do futuro. Sabe-se que todos os elementos analisados estão atrelados a aspectos espaciais de planejamento, e que um número de questões locacionais e gerenciais influenciam na forma urbana como, por exemplo, questões de centralidade e dispersão. Segundo a Agenda, a forma urbana é intrinsecamente conectada ao caráter da cidade e ao seu genius loci. ${ }^{2}$ Dessa maneira, o planejamento regional deve assegurar a hierarquia e a clara função nas relações

2 Segundo Norberg-Shulz, genius loci é um conceito romano de que toda entidade tinha o seugenius, o seu espírito guardião. Esse espírito, responsável pelas pessoas e lugares, determinava seu caráter ou a sua essência. 
intra-urbanas e regionais. Reconhece a positiva vantagem em desenvolver o conceito de cidades cluster, cada uma com identidade e proposta claras, conectadas por um transporte eficiente. Reforça, dessa maneira, o modelo de uma cidade sustentável: cidades como uma série de vilas ou comunidades conectadas.

O desenvolvimento de uma compreensão integrada e a evolução para um processo mais democrático requer melhoria na comunicação e maior participação comunitária nos processos de decisão. Há a necessidade contínua de se mudar a ênfase do planejamento de um approach prescritivo a um processo baseado nas necessidades dos citadinos. A noção de um approach mais centrado no cidadão expressa as necessidades humanas de viver nas cidades, temática central da Nova Carta de Atenas.

As dez recomendações - satisfazendo as necessidades do amanhã e as aspirações dos cidadãos

A síntese da análise para os possíveis desdobramentos de uma forma urbana sustentável define recomendações necessárias para a atuação do urbanista: uma cidade para todos, envolvimento real, contato humano, continuidade do caráter, benefícios de novas tecnologias, aspectos ambientais, atividades econômicas, movimento e acesso, variedade e diversidade, saúde e segurança.

As recomendações referem-se, primeiro, a "uma cidade para todos", que traz reflexões sobre a pobreza urbana e declínio de coesão social, e define que o processo de planejamento de cidades deve assegurar a incorporação de todos os grupos na vida econômica, social e cultural. Quanto ao "envolvimento real" o urbanista deve capacitar e encorajar as diversas formas de participação comunitária nas decisões. Na questão dos "benefícios das novas tecnologias" alerta para o desenvolvimento de tecnologia que terá um rebatimento na estrutura da cidade, na possibilidade de promoção de descentralização de atividade e acesso igualitário às informações.

Nas recomendações de "contato humano" e"continuidade do caráter", soluções de design maisconscientes em relação a uma maior qualidade espacial são ressaltadas. No "contato humano", a atuação deve ser expressa em vários níveis hierárquicos espaciais (lote, vizinhança, bairro, cidade, região), sociais e administrativos. Ressalta a re criação das chamadas áreas de domínio público public domain), entendido como lugar onde o senso de comunidade, a vitalidade e atividade social devam ser desenvolvidos e reforça a necessidade de espaços abertos e regeneração de áreas abandonadas. A "continuidade do caráter" critica a destruição sistemática do tecido urbano, a necessidade de salvaguardar os elementos tradicionais e a identidade dos ambientes urbanos. Soluções de design devem ser basilares em análises culturais, históricas, visuais, funcionais e qualidades existentes.

Os "aspectos ambientais" estão no cerne das recentes discussões e, como afirmam os princípios do desenvolvimento sustentável, deverão ser a essência do Planejamento Urbano. Neste sentido, deverá ser direcionado para a conservação dos recursos não renováveis, a conservação de energia e de tecnologias limpas, a redução dos vários tipos de poluição, evitar o desperdício e promover a reciclagem e redução, e a necessária flexibilização das decisões com o suporte de comunidades locais.

Recomendações como "atividades econômicas", "movimento e acesso" e "variedade e diversidade" estão sobrepostas nas relações centrais de uso do solo nas cidades. Nas "atividades econômicas" é necessário um approach integrado para regeneração urbana na inter-relação de aspectos físicos, estruturas sociais e revitalização econômica. Quanto ao "movimento e acesso", a promoção de acessibilidade requer o reconhecimento de que o uso do solo e o sistema de transportes devem ser concebidos de forma única, diminuindo a dependência de veículos individuais. Em relação à "variedade e diversidade", o abandono pela monofuncionalidade do uso do solo e a promoção de usos mistos compatíveis deverão ser enfatizados, incrementando a vitalidade e variedade no tecido urbano. Acrescenta a necessidade de "designs inovadores" para habitações de baixo custo.

Finaliza com as diretrizes de "saúde e segurança" que deverão ser priorizadas, e que estão relacionados com desastres naturais, intervenções militares, conflitos sociais e criminalidade. Reforça que pobreza e problemas de saúde acarretam a privação e constante desumanização nas cidades. A promoção de "cidade saudável" pode ser alcançada elevando a habitabilidade e melhorando as questões ambientais. Conclui que a cidade do Século XXI deve ser criada não somente por um plano diretor (masterplan)mas no processo de negociação, centrado no bem-estar do cidadão. 


\section{Considerações finais}

A Carta de Atenas de 1933, que repercutiu como manual dos urbanistas modernos, talvez em face de necessidade de recomposição de tecidos urbanos pós-guerras e em consonância com o modelo capitalista de produção. A Nova Carta de Atenas de 1998, pelo caráter dogmático da primeira, conduz às reflexões e críticas acumuladas nas últimas décadas e incorpora os principais preceitos de desenvolvimento sustentável.

A reversão de conceitos pode ser observada principalmente na atuação do arquiteto como o "grande mestre" detentor das verdades, a um coreógrafo do desenvolvimento. O domínio científico dos planejadores à ênfase na efetiva participação social nas decisões de planejamento (empowerment) é considerado como temática central do documento. Desta maneira, a Nova Carta de Atenas insere-se na visão do ambientalismo moderado, de viés antropocentrista e desenvolvimentista, semo questionamento do tipo de desenvolvimento, enfatizando a consciência ambiental necessária ao futuro para a perpetuação dos ambientes urbanos para o homem (FOLADORI, 2001). Conduz sobre a forma urbana desejável para o futuro de uma cidade sustentável, o modelo de uma série de vilas ou comunidadesinterligadas.

Observa-se o caráter eurocêntrico na análise dos problemas urbanos e das proposições espaciais, que situam-se em dimensões diferenciadas nos âmbitos sociais, econômicos e culturais de outras realidades urbanas. Destarte, a análise das recomendações sugere uma mudança de atitude na concepção dos espaços intersticiais urbanos, que devem ser repensados por arquitetos-urbanistas na incorporação de outros valores.

Nesse sentido, Leff aponta duas linhas de pensamento: racionalidade ambiental e saber ambiental. O primeiro, em linhas gerais, inclui novos princípios teóricos e novos meios instrumentais para reorientar as formas de manipulação produtiva da natureza. Essa racionalidade está sustentada por valores tais como qualidade de vida, identidades culturais, sentidos de existência, que não aspiram a alcançar um status de cientificidade. E, no segundo, saber ambiental, ultrapassa o campo da racionalidade científica e da objetividade teórica, de onde emergem novas estratégias conceituais (LEFF, 2001). Na reflexão do saber ambiental de Leff e na construção dos ambientes urbanos, há a necessidade de sobreposição de diferentes valores e olhares que deverão ser incorporados nas práticas de organização de cidades.

As considerações da Nova Carta de Atenas sintetizam recomendações de caráter não inovador, que vêm sendo discutidas nas últimas décadas. Porém, apresentam um desafio profissional, de entender o espaço urbano com novos parâmetros qualitativos e centrados nos cidadãos que deverão ser os efetivos partícipes na construção de ambientes mais sustentáveis.

\section{REFERÊNCIAS}

CHOAY, Françoise. O urbanismo. São Paulo: Perspectiva, 1979.

BROADBENT, Geoffrey. Emerging concepts in urban space design. Londres: Spon Press, 1996.

DEL RIO, Vicente. Introdução ao desenho urbano no processo de planejamento. São Paulo: Pini, 1990.

ECTP. New charter of Athens, 1998. (mimeo)

LEFF, Enrique. Epistemologia ambiental. São Paulo: Cortez, 2001.

FOLADORI, Guillermo. Una tipología del pensamiento ambientalista. In: PIERRI, N.; FOLADORI, G. (orgs). Sustentabilidad? Desacuerdos sobre el desarrollo sustentable. Montevideo: Trabajo y Capital, 2001.

FLORIANI, Dimas. A complexidade ambiental nos convida a dialogar com as incertezas da modernidade. Desenvolvimento e Meio Ambiente: Teoria e Metodologia em Meio Ambiente e Desenvolvimento, n. 4. Curitiba: UFPR, 2001.

MAGALHÃES, Manuela Raposo. Arquitetura Paisagística: morfologia e complexidade. Lisboa: Editorial Estampa, 2001.

VICENTINI, Yara; RIZEK, Cibele S. Teorias urbanas e o tema da natureza. (mimeo) (s/d). 